\title{
Fuzzy Adaptive Control Applied to a Hybrid Electric- Power Generation System (HEPGS)
}

\author{
Guillermo Valencia Ochoa ${ }^{1}$, Camilo Blanco ${ }^{2}$, Carlos Martinez ${ }^{1}$ and Erni Ramos ${ }^{1}$ \\ 'Mechanical Engineering, Research Group in Efficient Energy Management, Kai, College of Engineering, \\ Universidad del Atlantico, Atlantico, Colombia; guillermoevalencia@mail.uniatlantico.edu.co, \\ camiloblanco2015@gmail.com, esramos@mail.uniatlantico.edu.co \\ ${ }^{2}$ Chemical Engineering, Research Group in Efficient Energy Management, Kai, College of Engineering, \\ Universidad del Atlantico, Atlantico, Colombia; maar_04@hotmail.com
}

\begin{abstract}
Objectives: Application of a fuzzy adaptive control to a commuted Hybrid Electric Power Generation System (HEPGS) for different case studies. Methods: The system is integrated by a $400 \mathrm{~W}$ wind turbine, a Polymer Electrolyte Membrane Fuel Cell (PEMFC), and a solar photovoltaic panel which represent the three sources of energy of the system, where the oxygen and hydrogen flow are controlled variables, and the wind power, solar power and electrical demand are uncontrolled variables considering two meteorological station, Puerto Bolivar and Ernesto Cortissoz. Findings: The transient responses of the system with respect to the variation of the solar radiation and wind velocity, regarding to the meteorological and geographical conditions of the zone, are presented as results of the manipulation of the reactant flow in the PEMFC. It was possible to propose an adaptive fuzzy PID which responses were compared to the standard responses of achieved by a classical PID controller, the responses of the fuzzy adaptive PID were 37,4 and 45,4\% improved for the meteorological stations Puerto Bolivar and Ernesto Cortissoz respectively for an electrical demand of $200 \mathrm{MW}$. Finally, a fuzzy logic control model was proposed and tested, demonstrating an improved performance than a classical PID. Application: These systems are able to be applied in rural zones where the on grid energy systems are not supplied. In addition, a hybrid energy system may be improved through the implementation of novel control techniques, so that can be possible to increase the efficiency and improve the performance of the HEPGS.
\end{abstract}

Keywords: Adaptive Fuzzy PID, Fuel Cells, Hybrid Energy System, Solar Energy, Wind Energy

\section{Introduction}

The application of new control methods based on algorithms of fuzzy adaptive controllers represents one of the most relevant industrial fields in recent years $\frac{1-3}{}$, due to the fact that this control method allows to get a better performance and optimization of the available resources ${ }^{4-6}$, therefore it is an important factor in the cost reduction associated to industrial process and unnecessary raw material expenses $2, \frac{2,8}{}$.
Most of the currently used control strategies are based on the rules that govern the classical PID which have demonstrated a good performance in hybrid systems control for a long time $\frac{8.9}{.}$. However, the application of an adaptive fuzzy control system resulted in a real improvement in the dynamic and transient properties of the system compared to a classical PID controller, ${ }^{9,10}$, resulting in a lower energy consumption and lower operative costs of the system.

${ }^{*}$ Author for correspondence 
The aim of this research is to performance an evaluation of a multivariable adaptive fuzzy control applied to a power generation hybrid energy systems integrated by a wind turbine, a solar cell and a PEM, where the controlled variables are hydrogen flow and oxygen flow entering to the fuel cell in order to compensate the variations due to disturbances presented by uncontrolled variables such as the wind velocity and solar irradiance, highly influenced by geographical and meteorological conditions according to the location of the meteorological stations Puerto Bolivar and Ernesto Cortissoz located in the departments of La Guajira and Atlantico respectively, and the electrical demand of the target population ${ }^{11}$.

Finally, it was possible to set up a multivariable power generation hybrid energy system so that to satisfy the electrical demand of the target population, promoting the use of energy policies in Colombia such as law 1715 which regulates the integration of renewable energies to the national energy grid $\frac{12}{2}$, implying an important development to the future implementation of energy system in the off grid zones of the Colombian Caribbean Region.

\section{Description of the System}

A simulation of a hybrid energy system is presented in this research, this HEPGS is integrated by three different energy sources, furthermore, this model presents the application of a MIMO (Multiple Inlets Multiple Outlets) adaptive control in order to improve the efficiency of the system as well as obtain a higher equilibrium in the energy supply converted from the three different sources. The hybrid system mentioned above is integrated by a wind turbine which supply electrical energy from wind, a solar cell which supply electricity from solar photovoltaic energy, and a PEM fuel cell which supply electricity converted from chemical energy due to the reaction of hydrogen with oxygen, additionally, the system is integrated by an electrolyzer, the electrical demand of the target population, and the adaptive fuzzy controller as shown in the scheme of the hybrid system as in Figure 1.

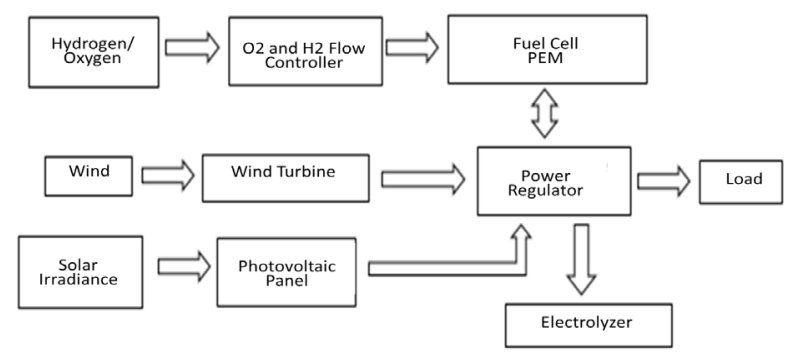

Figure 1. Basic scheme of a hybrid energy power generation system.

\subsection{Dynamic Model of the Fuel Cell}

This section describes the dynamic model of a fuel cell considering the different parameters and variables needed to model the PEM in a dynamic response $e^{13,14}$.

According to the fuel cell data sheet, the thermodynamic potential $\mathrm{E}$ is defined with the Nernst equation using the equation (1).

$E=1.229-0.85 \times 10^{-3}(T-298.15)+4.3085 \times 10^{-5} T\left(\ln p_{h_{2}}+0.5 \ln p_{o_{2}}\right)$

Here $\mathrm{T}$ is the temperature of the fuel cell in $\mathrm{K}$.

Thus, the oxygen concentration solved in the gas - liquid interphase is defined by the Henry's law as in equation $(2)^{15}$.

$C_{\mathrm{O}_{2}}=\frac{\mathrm{PO}_{2}}{5.8 \times 10^{6} \exp (-498 / \mathrm{T})}$

Then, the excessive voltage due to the activation of the fuel cell and the internal resistance are developed from the empirical analysis as in equations (3) and (4).

$\eta_{\text {act }}=-0.96514+0.00312 \mathrm{~T}-0.000187 \ln (i)+7.4 \times 10^{-5} \mathrm{Tlnco}_{2}$

$R_{\text {int }}=0.01605-3.5 \times 10^{-5} \mathrm{~T}+8 \times 10^{-5} i$

Where $i$ is the current and $R_{\text {int }}$ is the internal resistance in the fuel cell.

Therefore, the current and the activation resistance in the fuel cell are related as in the equation (5).

$R_{a}=-\frac{\eta_{a c t}}{i}$ 
While the output voltage of the fuel cell is calculated as in equation (6).

$$
V=E-V_{a c t}+V_{\text {ohmic }}
$$

Here $\mathrm{V}_{\text {act }}$ is the activation voltage and pohmic is the ohmic voltage of the fuel cell.

The differential equation so that to obtain the activation voltage of the fuel cell is described in equation (7).

$\frac{d_{V_{a c t}}}{d t}=\frac{i}{C}-\frac{V_{a c t}}{\frac{R_{a}}{C}}$

The voltage loss and the total voltage in the fuel cells are given by the equations (8) and (9).

$V_{\text {ohmic }}=-i R_{\mathrm{int}}$

$V_{\text {stack }}=65 V_{\text {cell }}$

The pressure in the cathode and anode are given by equations (10) and (11).

$\frac{V_{a}}{R T} \frac{d P_{H_{2}}}{d t}=\dot{m}_{H_{2}-i n}-\left(\rho_{H_{2}} U A_{r}\right)_{\text {out }}-\frac{i}{2 F}$

$\frac{V_{c}}{R T} \frac{d P_{O_{2}}}{d t}=\dot{m}_{O_{2}-i n}-\left(\rho_{O_{2}} U A_{r}\right)_{\text {out }}-\frac{i}{4 F}$

The thermal energy balance of the fuel cell is shown in equation (12).

$\frac{d T}{d t}=65 i^{2} \frac{\left(R_{a}+R_{i n t}\right)}{C_{h t}}-\frac{\left(T-T_{r}\right)}{R_{t} / C_{h t}}$

Therefore, according to the Faraday's law, the hydrogen production rate in a fuel cell is given by equation (13).

$\eta_{H_{2}}=\frac{\eta_{F} \eta_{c} i_{e}}{2 F}$

Finally, the relation between the real and theoretical hydrogen production in the electrolyzer is obtained from equation (14).
$\eta_{F}=96.5 \exp \left(\frac{0.09}{i_{e}}-\frac{75.5}{i_{e}^{2}}\right)$

\subsection{Dynamic Model of the Solar Photovoltaic Panel}

Similarly to the model of the fuel cell, in this section the equations for the dynamic modeling of the solar cell are described using the parameter and variables needed for the adaptive fuzzy controller of the HEPGS $\frac{16-18}{}$.

Since the photovoltaic potential is directly related to the solar irradiance through a complete year ${ }^{19,20}$, this behavior, as shown in Figure 2, must be modeled as in equations (15)-(19).

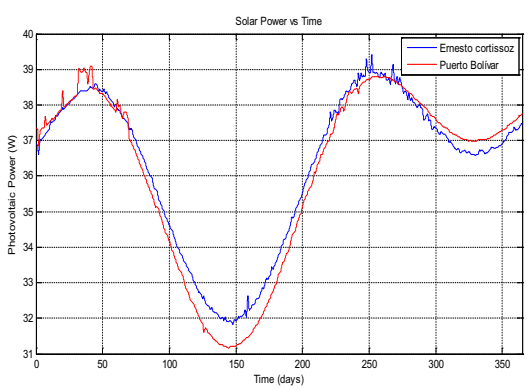

Figure 2. Dynamic behavior of the photovoltaic potential for the meteorological stations Ernesto Cortissoz and Puerto Bolivar.

The modeling of the photovoltaic cell is defined based on the modeling ${ }^{21}$, thus the photocurrent in solar cell is determined as in equation (15).

$I_{p h}=\left[I_{S C r}+K_{i}(T-298)\right] \times \frac{\lambda}{1000}$

Similarly, the inverse saturation current is defined as in equation (16).

$I_{r s}=I_{S C r} /\left[\exp \left(\frac{q V_{O C}}{N_{s} k A T}\right)-1\right]$

However, the saturation current is directly related to the photovoltaic cell, therefore, the saturation current is expressed in the equation (17).

$I_{O}=I_{r s}\left[\frac{T}{T_{r}}\right]^{3} \exp \left[\left(\frac{q E_{g \circ}}{B k}\right)\left(\frac{1}{T_{r}}-\frac{1}{T}\right)\right]$ 
Thus, the output current in the photovoltaic cell is obtained from equation (18).

$I_{P V}=N_{P} \times I_{p h}-N_{p} \times I_{0}\left[\exp \left[\left(\frac{q \times\left(V_{P V}+I_{P V} R_{S}\right)}{N_{S} A k T}\right)-1\right]\right.$

Here, $V_{P V}=V_{O C}, N_{P}=1$ and $N_{S}=36$ are param eters assigned for the modeling of the solar cell.

Finally, the total power of the photovoltaic cell is obtained from the operation of the output current times the voltage used in the solar cell as in equation (19)

\subsection{Dynamic Model of the Wind Turbine}

The third source of energy in the hybrid system is the wind energy, which modeling is developed based on the work $^{22}$. Since the wind potential is directly related to the wind speed and direction, which are uncontrolled variables, it is necessary to model the wind potential through the time taking a reference altitude of 100 meter high $\frac{23}{}$, as shown in Figure 3.

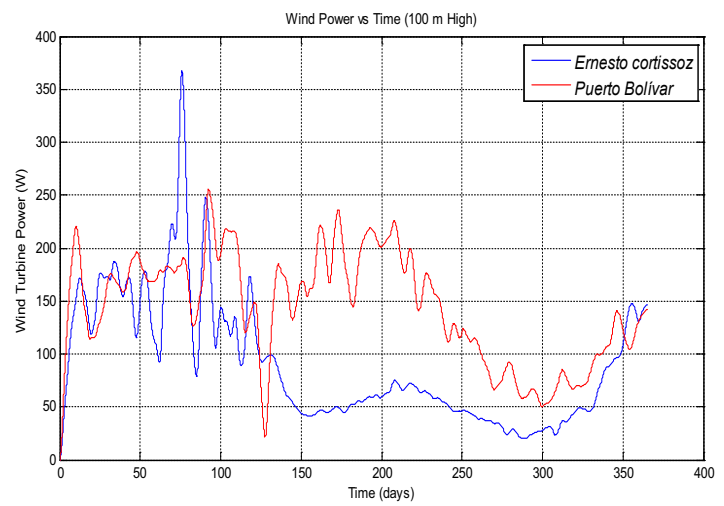

Figure 3. Dynamic behavior of the wind power through a complete year at 100 meters high.

The dynamic behavior of the wind turbine is presented as in equation (20).

$\frac{y(s)}{x(s)}=\frac{0.25}{s^{2}+0.7 s+0.25}$

The power curve of the wind generator model Air 403 is shown as in Figure 4, where the values of the wind power with respect to wind speed are supplied. This model is able to generate a maximum output of $800 \mathrm{~W}$ at $40 \mathrm{mph}$.

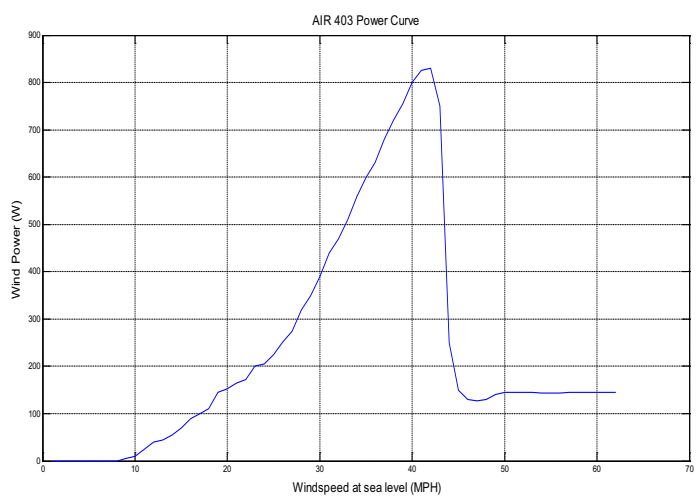

Figure 4. Air 403 power curves - Source: Air 403 owner's manual.

\section{Controllers}

This section describes two types of controllers able to control the process of power generation with the HEPGS, initially the classical PID controller, the most commonly controller used in this process $\frac{24,25}{}$, will be described and compared to a novel method which is the fuzzy adaptive PID controller.

\subsection{Classical PID Controller}

For the classical PID controller, the tuning process was made using the Ziegler-Nichols method in open loop, with a number of tests in open loop that allowed to approximate the values for the plant to a First Order Process plus Dead Time (FOPTD).

Firstly, the gain, thao and dead time of the first order equation are determined based on Ziegler-Nichols method. This procedure was conducted for a step change between 0.005 and $0.008 \mathrm{~mol} / \mathrm{s}$ in the hydrogen flow, keeping the oxygen flow constant under steady state, afterwards the procedure was conducted with the oxygen flow as a variable and the hydrogen floe constant in steady state. Therefore, the FPODT equations obtained for the variation of oxygen and hydrogen are shown as in equations (21) and (22).

$$
\begin{aligned}
& \text { FOPDT (Oxygen })=\frac{125 e^{-1,213 s}}{18,207 s+1} \\
& \text { FOPDT (Hydrogen })=\frac{62 e^{-0,2125 s}}{23,2275 s+1}
\end{aligned}
$$


Subsequently, with the values obtained in equations (21) and (22), the tuning process of the controller was carried out using the Ziegler-Nichols rules; therefore, the tuning parameters for the oxygen and hydrogen of the PID controller are shown in Table 1.

Table 1. Parameters from Ziegler-Nichols tuning rules

\begin{tabular}{|l|l|l|l|l|}
\hline & $\mathrm{Kc}$ & $\mathrm{Ti}$ & $\mathrm{Td}$ & $\mathrm{t} / \mathrm{to}$ \\
\hline Oxygen & 0,14409 & 2,426 & 0,606 & 0,067 \\
\hline Hydrogen & 2,1155 & 0,425 & 0,10625 & 0,009 \\
\hline
\end{tabular}

\subsection{Fuzzy Adaptive PID Controller}

The adaptive fuzzy PID controller, used to regulate the PEM, was attuned with the selection of input variables such as the voltage error, the voltage error derivate, and the electrical current in the fuel cell, which are variables considered as highly relevant for the mathematical behavior of the system. In the other hand, the proportional, integral, and derivative gain for each controller are considered as output variables for the tuning parameters of the hydrogen and oxygen controllers.

The adaptive fuzzy controller is integrated bye an input fuzzy system which constantly adapts the PID controller as shown in Figure 5.

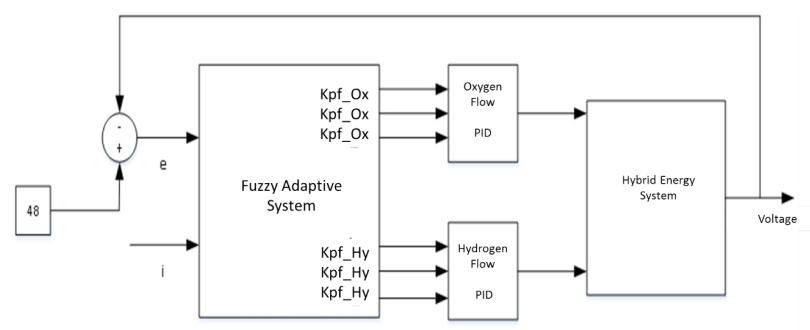

Figure 5. Fuzzy adaptive system of the HEPGS.

The fuzzy adaptive block takes the signal error and the electrical current as input variables, afterwards based on a set of fuzzy rules, the block will send the gain values calculated by the fuzzy system towards the PID controllers, these blocks carry out the mathematical operation shown in equations, so that to obtain the final gain values for both PID controllers of oxygen and hydrogen flow.

$K_{P_{-} \propto x}=K_{P_{-} o x}^{*}+K_{P_{f_{-}} \propto x}$
$K_{P_{-} \propto x}=K_{P_{-} o x}^{*}+K_{P_{f_{-}} \propto x}$
$K_{d_{-} 0 x}=K_{d_{-} 0 x}^{*}+K_{d_{-} 0 x}$

$K_{P_{-} H i}=K_{P_{-} H i}^{*}+K_{P_{f_{-} H i}}$

$K_{i_{-} H i}=K_{i_{-} H i}^{*}+K_{i f_{-} H i}$

$K_{P_{-} H i}=K_{d_{-} H i}^{*}+K_{d f_{-} H i}$

Here Kp_Ox, Ki_Ox, Kd_Ox, Kp_Hy, Ki_Hy, and Kd_Hy are the obtained vales after the tunning process. Meanwhile $\mathrm{Kp}^{*}{ }_{-} \mathrm{Ox}, \mathrm{Ki}^{*} \_\mathrm{Ox}, \mathrm{Kd}^{*} \_\mathrm{Ox}, \mathrm{Kp}^{*}{ }_{-} \mathrm{Hy}, \mathrm{Ki}^{*}{ }_{-} \mathrm{Hy}$, and $\mathrm{Kd}^{*}$ _Hyaare the initial values obtained from the classical PID. Finally, Kpf_Ox, Kif_Ox, Kdf_Ox, Kpf_Hy, Kif_Hy and Kdf_Hy are the final calculated values after the tuning of the adaptive fuzzy PID.

After the application of equations, membership functions and surface controls are obtained from the gains calculated for the adaptive fuzzy PID, which regulates the oxygen and hydrogen flow, with respect the error, the derivate of the error, and the electrical current as shown in Figures 6-8.
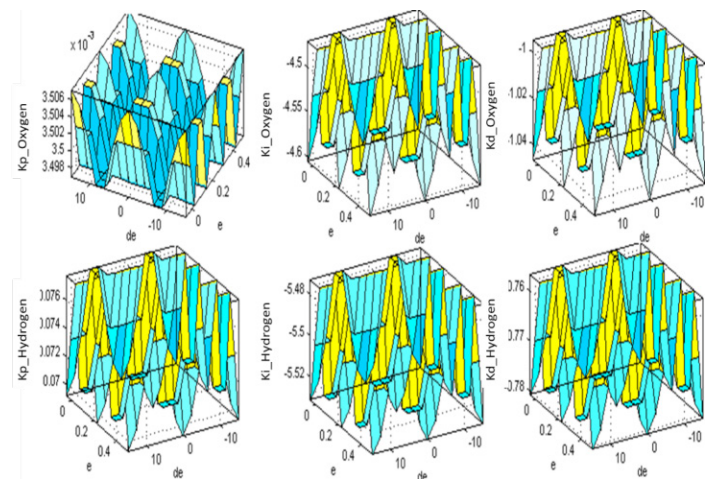

Figure 6. Surface control of error with respect to the derivate of error.

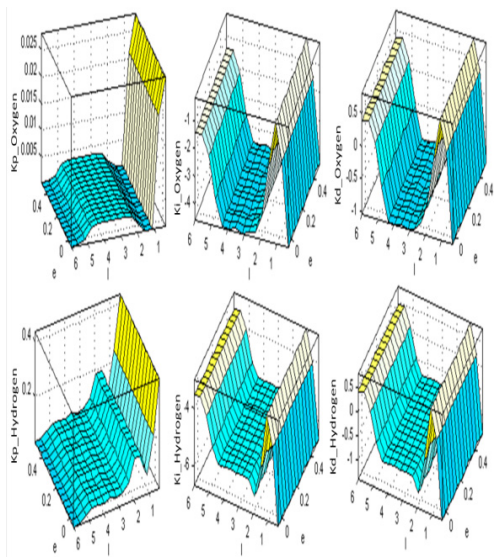

Figure 7. Surface control of error with respect to the electrical current. 

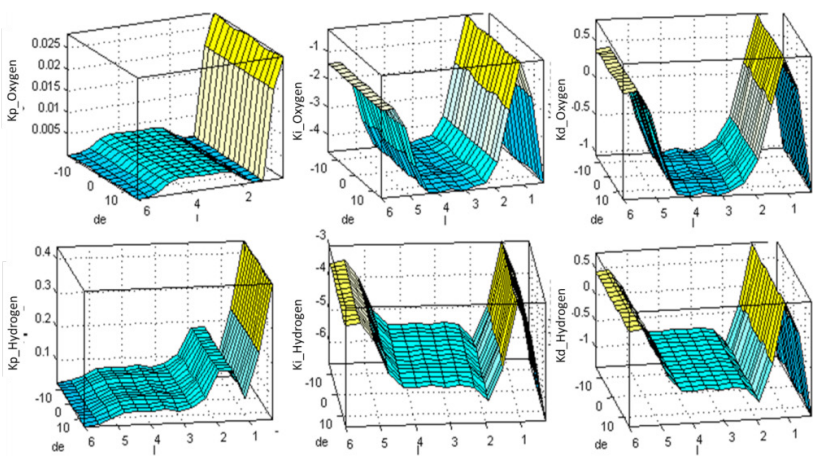

Figure 8. Surface control of the derivate of error with respect to the electrical current.

The resultant control surface for each of the tuning parameters with respect to the input variables of the error and the derivate of error is shown in Figure 6.

Figure 7 shows the resultant surface control for each of the tuning parameter of the adaptive fuzzy PID with respect to the input variables of the error and the electrical current.

Figure 8 shows the resultant surface control for each of the tuning parameter of the adaptive fuzzy PID with respect to the input variables of the derivate of error and the electrical current.

\section{Results}

Under dynamic conditions the HEPGS must meet and standard calculated electrical demand of $200 \mathrm{~W}$. The results for voltage and current through the time obtained from the control process of an adaptive fuzzy PID, a fuzzy logic control and, a classical PID are presented and compared for the meteorological stations as shown in Figure 9 and 10 for Ernesto Cortices, and Figures 11 and 12 for Puerto Bolivar. The design and utilization of fuzzy logic controllers works as a reference point for comparison, additionally the inclusion of fuzzy logic controllers in this research allows verifying the better performance of fuzzy controllers over the classical controllers.

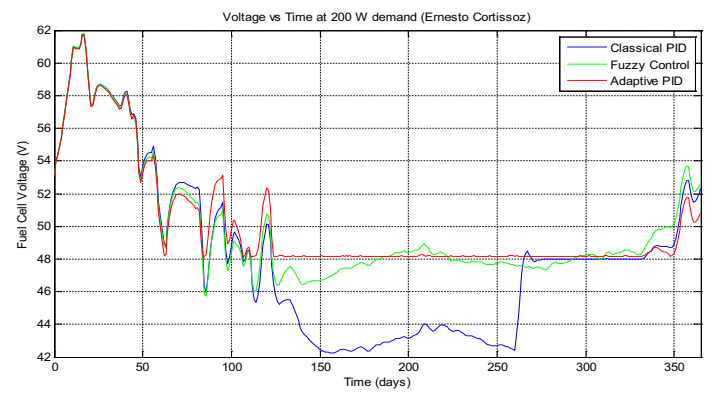

Figure 9. Fuel Cell voltage variation for Ernesto Cortissoz.

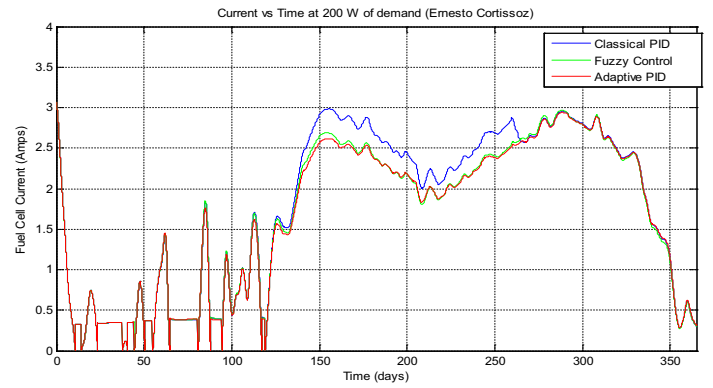

Figure 10. Fuel Cell electrical current variation for Ernesto Cortissoz.

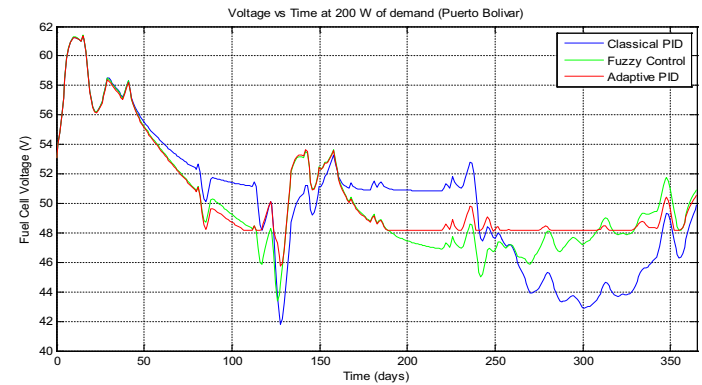

Figure 11. Fuel cell voltage variation for Puerto Bolivar.

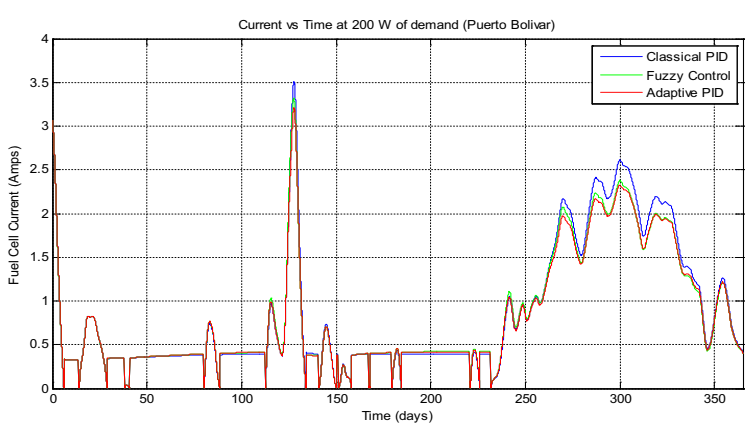

Figure 12. Fuel cell electrical current variation for Puerto Bolivar.

The variations of the output voltage and the electrical current in the fuel cell of the HEPGS, for a standard year, are shown in Figure 9 and Figure 10 respectively. There are noticeable random oscillations during the first four months of the year for both results. This phenomenon is explained due to the fact of sudden variations in the wind speed, which did not allow an effective control response for the fuzzy adaptive PID. Subsequently, the amplitude of the oscillations is noticeably smaller, making possible a better and more efficient response for the controllers.

For Puerto Bolivar, it is possible to observe that appears oscillation with small amplitude during the first four months of the year for the output results, output voltage 
and electrical current in the fuel cell. During the following month, it is possible to observe oscillation with higher amplitude that did not allow a proper process control. After this turbulent period, the adaptive fuzzy PID presents a strong stability with respect the other two controllers.

The observable behavior of the control response for the voltage and the electrical current for both meteorological stations is quite similar during the first 30 days of simulation. This is due to the fact that the dead time presented in the dynamic behavior of the HEPGS, where the manipulated variables do not affect the variables for the control process.

\subsection{Performance of Controllers}

An indicator for the performance for the controllers was determined using the Integral Absolute Error (IAE) technique. An electrical demand of $200 \mathrm{~W}$ was selected as a reference control performance testing the favorable response of each of the controllers' studies such as classical PID, fuzzy logic control, and fuzzy adaptive PID.

For Ernesto Cortissoz, the IAE values calculated are 1420,61 for a classical PID; 866,84 for the fuzzy logic control, and 775,80 for the fuzzy adaptive PID.

In the other hand, the calculated values of the IAE for Puerto Bolivar are: 1492,63 for a classical PID; 1064,54 for the fuzzy logic control, and 934,76 for the fuzzy adaptive PID.

In addition, the IAE was calculated conducting three modifications of the electrical demand at values of $100 \mathrm{~W}$, $150 \mathrm{~W}$, and $250 \mathrm{~W}$ are shown as in Table 2. It is noticeable that the fuzzy adaptive PID presents a higher performance and improved efficiency, with respect to the variation in the electrical demand than the classical PID and the fuzzy logic controller.

\subsection{Robustness Analysis}

In order to guarantee a strong control system, a robustness analysis is conducted in this research so that to determine the robustness interval for the fuzzy adaptive controller before a variability in the tuning parameters. The domain of discourse was altered in percentages of $10 \%, 20 \%,-10 \%$, and $-20 \%$.

The positive alterations represent an increase in the superior limit of the domain of discourse with respect to the output variables; this alteration generates tuning parameter higher than the values set in the initial interval.

Meanwhile, the negative alterations imply a decrease in the bottom limit of the domain of discourse with respect to the output variables; this alteration generates lower tuning parameter than the values set in the initial interval.

The results for the robustness analysis for Ernesto Cortissoz are shown as in Figure 13. It is possible to observe consistency in the intervals which assure a proper performance of the fuzzy adaptive controller under alterations of the domain of discourse.

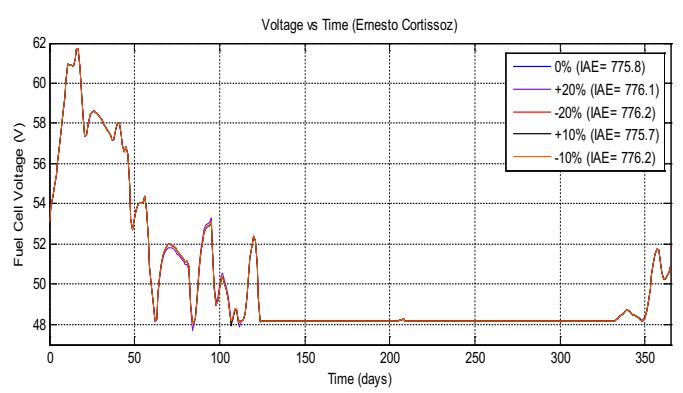

Figure 13. Robustness interval for a commuted HEPGS in Ernesto Cortissoz.

In the other hand, the results for the robustness analysis for Puerto Bolivar are shown as in Figure 14. It is noticeable that for an increase of $20 \%$ of the domain of discourse, the fuzzy adaptive controller does not keep the consistency as desired.

Table 2. Calculated IAE values for Ernesto Cortissoz and Puerto Bolivar at different electrical demands

\begin{tabular}{|l|c|c|c|c|c|c|}
\hline & \multicolumn{3}{|c|}{ Ernesto Cortissoz } & \multicolumn{3}{c|}{ Puerto Bolivar } \\
\hline & $100 \mathrm{~W}$ & $150 \mathrm{~W}$ & $250 \mathrm{~W}$ & $100 \mathrm{~W}$ & $150 \mathrm{~W}$ & $250 \mathrm{~W}$ \\
\hline Classical PID & 1604,7 & 1430,7 & 866,6 & 1593,1 & 1442,1 & 1406,9 \\
\hline $\begin{array}{l}\text { Fuzzy Logic } \\
\text { Control }\end{array}$ & 986,5 & 952,4 & 629,4 & 999,5 & 1035,6 & 954,1 \\
\hline Adaptive PID & 920,8 & 832,8 & 542,6 & 838,3 & 990,9 & 802,7 \\
\hline
\end{tabular}




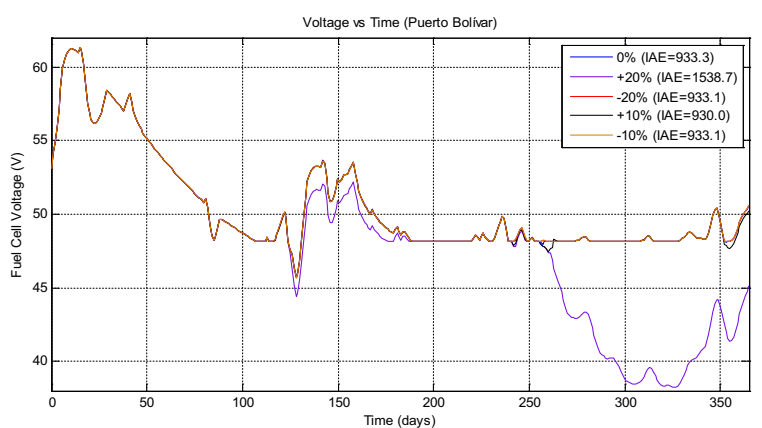

Figure 14. Robustness interval for a commuted HEPGS in Puerto Bolivar.

\section{Conclusions}

The control system under the rules of fuzzy logic achieved a better dynamic response than the classical PID due to the fact that fuzzy logic controllers are able to achieve a better performance for non linear systems as in the case of the HEPGS, which presents a high variability in the conditions of the electrical demand and natural disturbances in the wind speed and solar irradiance. Its adaptive structure based on fuzzy logic, allows adapting and adjusting the values of the gain from the controller to the most efficient.

After 120 days of running simulation, the adaptive fuzzy PID was able to settle the fuel cell voltage to a desired value through the manipulation of oxygen and hydrogen flow. Due to the wind speed presented high oscillations during the first 120 days of the year, the controller was not able to take a proper control action.

The fuzzy logic control allows finding out favorable responses with respect to the different dynamic simulation during the research. This is demonstrated by the different IAE values related to the electrical demand for which the adaptive fuzzy PID improved the IAE values in $42,62 \%$ and $47,63 \%$ for Ernesto Cortissoz and Puerto Bolivar respectively, compared to the performance achieved by the classical PID for a $100 \mathrm{~W}$ electrical demand. For an electrical demand of $150 \mathrm{~W}$ the improvements achieved are of $41,8 \%$ and 31,29 for Ernesto Cortissoz and Puerto Bolivar respectively; with an electrical demand of $200 \mathrm{~W}$, it was possible to achieve improvements of 45,39\% and 37, 37\% for Ernesto Cortissoz and Puerto Bolivar respectively; finally, with an electrical demand of $250 \mathrm{~W}$ it was possible to achieve improvements of 37, 38\% and 42, 95\% for Ernesto Cortissoz and Puerto Bolivar respectively.
Adaptive fuzzy PID kept stability and consistency in the performance with respect tu variation and changes in the electrical demand compared to the other controllers, guarantying that the domain of discourse allows working at different loads.

From the robustness analyses, it can be determined that the design of the fuzzy adaptive PID is strong enough before uncertainties in the model of the HEPGS. The robustness interval will be more than $1 \%$ in the performance of the controller, with exceptions to modifications that significantly increase the tuning parameters.

\section{References}

1. Long L, Zhao J. Adaptive fuzzy output-feedback dynamic surface control of MIMO switched nonlinear systems with unknown gain signs. Fuzzy Sets and Systems. 2015; 302:2751. Crossref

2. Torreglosa JP, Garcia-trivi-o P, Fernandez-Ramirez LM, Jurado F. Control based on techno-economic optimization of renewable hybrid energy system for stand-alone applications. Expert Systems with Applications. 2016; 51:59-75.

3. Wang B, Xu J, Cao B, Li Q, Yang Q. Adaptive mode control strategy of a multimode hybrid energy storage system. Energy Procedia. 2016; 88:627-33. Crossref

4. Lin W, Zheng C. Energy management of a fuel cell/ ultracapacitor hybrid power system using an adaptive optimal-control method. Journal of Power Sources. 2011; 196(6):3280-9. Crossref

5. Zahraee SM, Assadi MK, Saidur R. Application of artificial intelligence methods for hybrid energy system optimization. Renewable and Sustainable Energy Reviews. 2016; 66:617-30. Crossref

6. Baghsheikhi M, Sayyaadi H. Real-time exergoeconomic optimization of a steam power plant using a soft computing-fuzzy inference system. Energy. 2016, 114, pp. 868-884. Crossref

7. Sha GM. Hybrid renewable energy integration ( HREI ) system for subtropical climate in Central Queensland Australia. 2016, 96, pp. 1034-1053.

8. Iqbal MT. Simulation of a small wind fuel cell hybrid energy system. Renewable Energy. 2003, 28, pp. 511-522. Crossref 9. Ou K, Wang Y, Li Z, Shen Y. Feedforward fuzzyPID control for air flow regulation of PEM fuel cell system. International Journal of Hydrogen Energy. 2015, 40 (35), pp. 11686-11695. Crossref

10. Pan I, Das S. Fractional order fuzzy control of hybrid power system with renewable generation using chaotic PSO. ISA Transactions. 2016, 62, pp. 19-29. Crossref PMid:25816968 
11. UPME. PROYECCIÓN DE LA DEMANDA ELÉCTRICA Y POTENCIA MÁXIMA EN COLOMBIA. 2016, pp. 1-55.

12. Colombia C De. Ley $N^{\circ} 1715$. Bogota, Colombia. 2014, pp. $1-26$.

13. Khan MJ, Iqbal MT. Dynamic modeling and simulation of a small wind-fuel cell hybrid energy system. Renewable Energy. 2005, 30 (3), pp. 421-439. Crossref

14. Rakhtala SM, Shafiee Roudbari E. Fuzzy PID control of a stand-alone system based on PEM fuel cell. International Journal of Electrical Power \& Energy Systems. 2016, 78, pp. 576-590. Crossref

15. Valencia GE, Cubas G, Turizo JC, Chamorro RJ. Mimo generalized predictive control for a small wind turbine-fuel cell hybrid energy system. ASME 3rd International Conference on Energy Sustainability ASME; San Francisco,California. 2009. p. 1-6. Crossref

16. Garcia JG, Mantz R, De Battista H. Hybrid control of a photovoltaic-hydrogen energy system. Journal of Hydrogen Energy. 2008; 33:3455-9. Crossref

17. Rahim NA, Ping HW, Selvaraj J. Photovoltaic module modeling using Simulink/Matlab. Procedia Environmental Sciences. 2013; 17:537-46. Crossref

18. Hwang JJ, Lai LK, Wu W, Chang WR. Dynamic modeling of a photovoltaic hydrogen fuel cell hybrid system. International Journal of Hydrogen Energy. 2009; 34(23):9531-42. Crossref
19. Gil C, Vanegas M, Valencia G. Comparacion de los modelos Armstrong-prescott, bristow-campbell y Bird y Hulstrom para el calculo de irradiancia solar en el Carmen de Bolivar. Congreso de Eficiencia y Gestion Energetica; Cartagena, Colombia. 2016. p. 1-6.

20. Padilla RV, Demirkaya G, Goswami DY, Stefanakos E, Rahman MM. Heat transfer analysis of parabolic trough solar receiver. Applied Energy. 2011; 88(12):5097-110. Crossref

21. Pandiarajan N, Ramaprabha R, Muthu R. Application of circuit model for photovoltaic energy conversion system. International Journal of Photoenergy. 2012. Crossref

22. Sobotka K. A wind-power fuel cell hybrid system study. University of Iceland and University of Akureyri; 2009.

23. Shin J-Y, Ouarda TBMJ, Lee T. Heterogeneous mixture distributions for modeling wind speed, application to the UAE. Renewable Energy. 2016; 91:40-52. Crossref

24. Ulpiani G, Borgognoni M, Romagnoli A, Di Perna C. Comparing the performance of on/off, PID and fuzzy controllers applied to the heating system of an energy-efficient building. Energy and Buildings. 2016; 116:1-17. Crossref

25. Wai L, Wong YW, Rajkumar RK, Rajkumar RK, Isa D. Hybrid energy storage systems and control strategies for stand-alone renewable energy power systems. Renewable and Sustainable Energy Reviews. 2016; 66:174-89. Crossref 